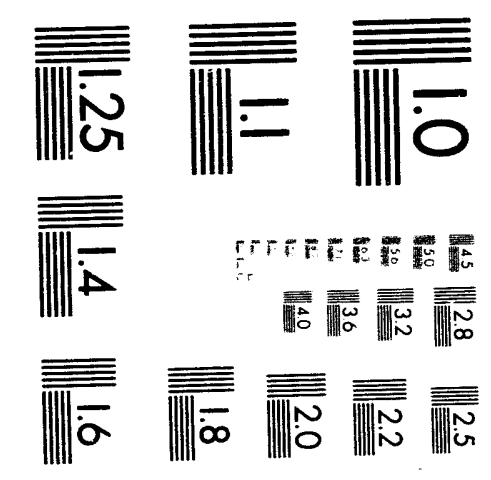



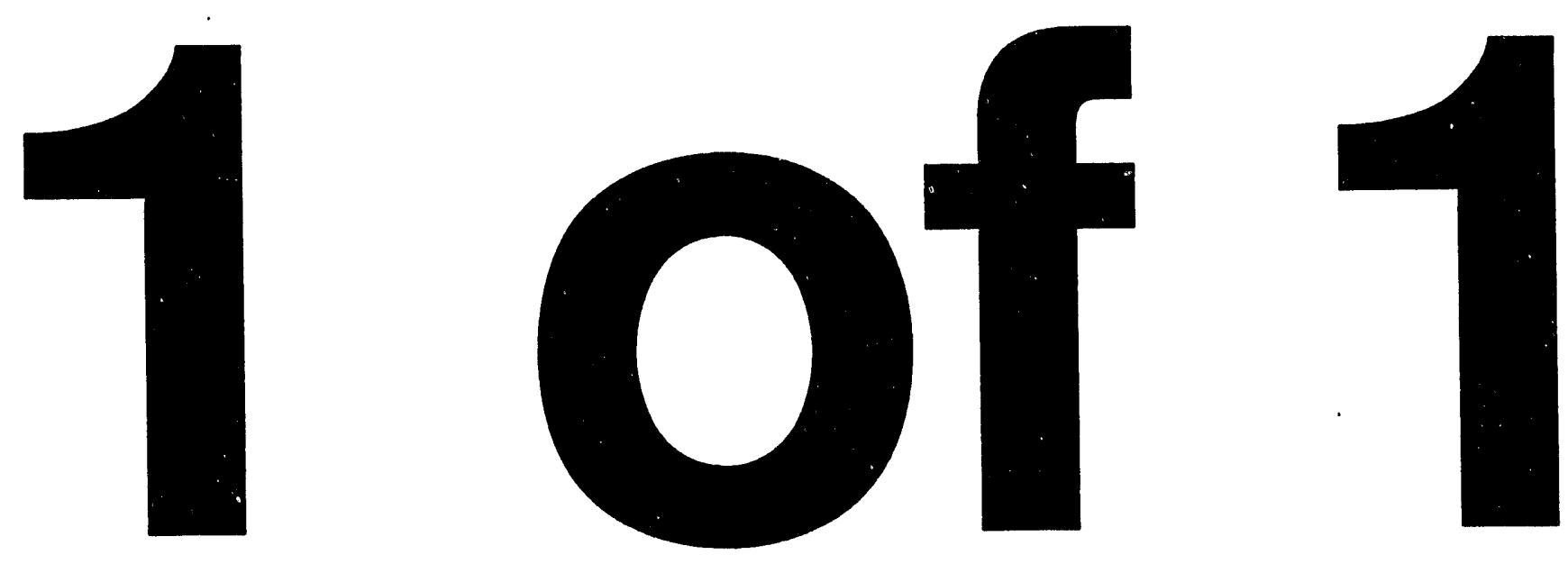


\title{
The Light Ion LMF and Its Relevance to IFE
}

\author{
R. E. Olson, G. O. Allshouse, D. L. Cook, T. R. Lockner, \\ M. G. Mazarakis, C. L. Olson, D. L. Smith \\ Sandia National Laboratories \\ Albuquerque, New Mexico 87185, USA
}

\begin{abstract}
The inertial confinement fusion (ICF) program at Sandia National Laboratories (SNL) is directed toward validating light ions as an efficient driver for ICF defense and energy applications. The light ion laboratory microfusion facility (LMF) is envisioned as a facility in which high gain ICF targets could be developed and utilized in defense-re ied experiments. The relevance of LMF technology to eventual inertial fusion energy (IFE) applications is assessed via a comparison of LMF technologies with those projected in the Light Ion Beam Reactor Assessment (LIBRA) conceptual reactor design study.
\end{abstract}

\section{INTRODUCTION}

A Laboratory Microfusion Facility (LMF) suitable for simulating nuclear weapon effects in the laboratory is the goal of the U.S. defense ICF program[1]. The Sandia National Laboratories (SNL) light ion LMF conceptuai design is based upon the projected on-target ion beam requirements of an $x$-ray driven ("indirect drive") capsule with a thermonuclear yield exceeding $500 \mathrm{MJ}$. These requirements are established by a combination of computer calculations and the existing ICF experimental database, which includes high intensity light ion driven target experiments in the PBFA-II facility at SNL[2]. The LMF ion beam requirement involves a two-step intensity input with peak on-target power of $\sim 700 \mathrm{TW}$ and a total on-target lithium ion energy of $\sim 14 \mathrm{MJ}$. The on-target power is supplied by twenty four individual ion beams. Two-stage extraction ion diodes with a standoff of four meters are used to generate the lithium ion beams. The high power ion diode conceptual design is based upon technologies being developed in the PBFA-II and Sabre facilities at SNL[2,3]. The accelerators which provide the necessary pulsed power to the ion diodes are based upon the successful Hermes III linear inductive voltage adder and magnetically insulated transmission line (MITL) technologies developed at SNL during the past 10 years[4].

The relevance of the light ion LMF technology to eventual inertial fusion energy (IFE) applications is assessed via a comparison of LMF technologies with those projected in the Light Ion Beam Reactor Assessment (LIBRA) studies [5-7]. The LIBRA studies are conceptual designs of light ion driven commercial fusion power reactors with accompanying economic analyses. The LIBRA pulsed power conceptual design is similar to our LMF concept with the added technology of repetitive magnetic (i.e., saturable reactor) pulse compressors and magnetic switching. The LIBRA economic analysis indicates that the light ion beam IFE approach is an excellent candidate for small, economic power plants of $\sim 500 \mathrm{MWe}$.

\section{THE ION-DRIVEN TARGET CONCEPT}

The SNL light ion ICF program is based upon an $\mathrm{x}$ ray driven ("indirect drive") target concept. The light ion beam target configuration is substantially different from either direct or indirect drive laser target configurations. With a light ion beam driver the fusion capsule is embedded within a foam-filled hohlraum, as shown schematically in Figure 1. The ions penetrate the external shell and deposit the bulk of their energy in the low density foam, which converts the ion beam energy into $x$ rays. The radiation, in turn, bathes the fusion capsule and provides the drive for the capsule implosion.

The goal of the experimental target effort on PBFA-II is to gain an understanding of the critical light ion beam hohlraum issues at specific power deposition levels comparable to those required by the LMF hohlraum. Such experiments will provide a key benchmarking of our ion deposition and radiation transport calculational capabilities. These capabilities include a three dimensional ion deposition code to model the effects of beam deposition nonuniformities on the x-ray uniformity at the capsule (including time and temperature dependent effects such as range shortening and hydrodynamic motion), a three- dimensional deterministic radiation transport code, and the two-dimensional LASNEX radiation hydrodynamics code. These state-of-the-art capabilities have been used in our LMF target design projections. The total ion beam power vs. time input for

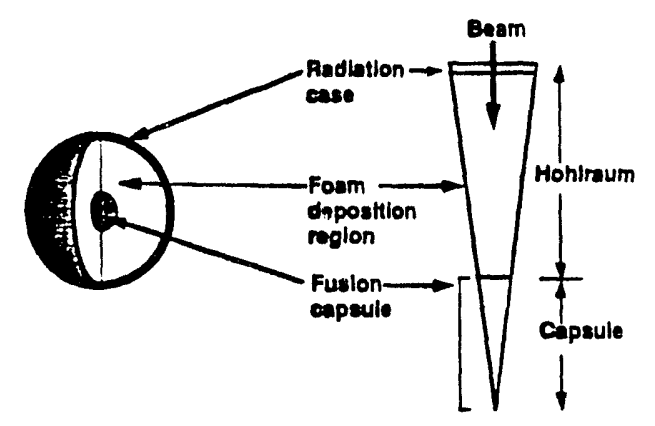

Figure 1: Basic configuration of an ion-driven ICF target. 


\section{DISCLAIMER}

This report was prepared as an account of work sponsored by an agency of the United States Government. Neither the United States Government nor any agency thereof, nor any of their employees, makes any warranty, express or implied, or assumes any legal liability or responsibility for the accuracy, completeness, or usefulness of any information, apparatus, product, or process disclosed, or represents that its use would not infringe privately owned rights. Reference herein to any specific commercial product, process, or service by trade name, trademark, manufacturer, or otherwise does not necessarily constitute or imply its endorsement, recommendation, or favoring by the United States Government or any agency thereof. The views and opinions of authors expressed herein do not necessarily state or reflect those of the United States Government or any agency thereof. 
a calculation with a 500 MJ fusion yield is shown in Figure 2. The calculations indicate that an illumination scheme involving a $2 \mathrm{~cm}$ diameter target and twelve individual ion beams with a $1.2 \mathrm{~cm}$ fwhm rotationallysymmetric Gaussian distribution will provide an adequately symmetric $x$-ray drive for the LMF capsule. Thus, we project that the required 700 TW peak ion beam power and 10:1 contrast ratio could be provided by using twelve ion beams at a power of 5.4 TW each and twelve ion beams at an on-target power of $54 \mathrm{TW}$ each. The hohlraum and deposition region design assumes that the beams are $\mathrm{Li}$ ions with an energy of $19-24 \mathrm{MeV}$ in the low power " $A$ " beams and 28-35 MeV in the high powe: " $B$ " beams.

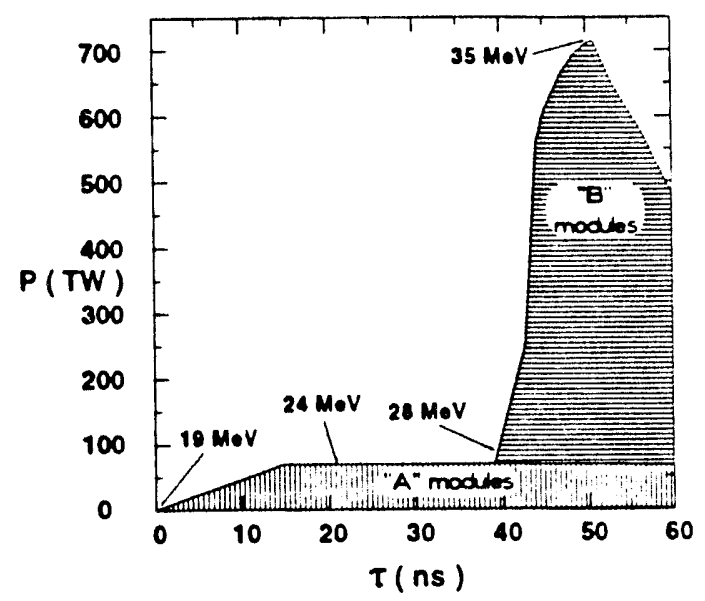

Figure 2: On-target ion beam power requirements for a predicted $500 \mathrm{MJ}$ thermonuclear yield.

\section{LMF DIODE, TRANSPORT, AND FOCUSING CONCEPTS}

An achromatic lens system is our baseline choice for beam focusing in the LMF [8]. In this scheme, each extraction diode produces an annular beam that drifts ballistically (at roughly constant radius) over several meters to a solenoidal lens. The beam is focused by the lens and propagates further in a ballistic mode to the target (Figure 3). This scheme is simple, attractive, and a direct extension of our present efforts on PBFA-II.

The diode-to-lens transport distance provides a means to use velocity ramping and beam bunching to obtain a factor of 2 increase in beam intensity on target. Intrinsic to this concept is the need for an accurately programmed voltage pulse and a transport length of about 4 meters. For an ion beam microdivergence of $6 \mathrm{mrad}$, a lens-to-target standoff length of about $1 \mathrm{~m}$ is assumed. A key engineering issue is whether a suitable lens system can be constructed to withstand the LMF blast and radiation effects at a distance of $1 \mathrm{~m}$ from the target. Preliminary work at the University of Wisconsin has given favorable results. but this issue merits further study [9].

The two-stage applied-B extraction ion diode is our present choice for the LMF beam generation. It promises adequate control over the ion beam voltage and current, good power coupling to the MITL, and the potential for reduced divergence as compared to a single stage diode. The

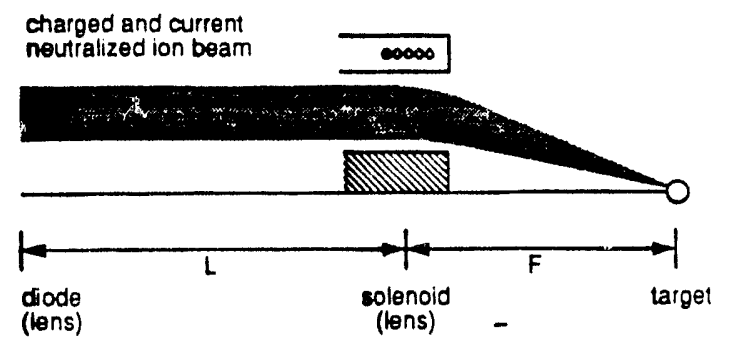

Figure 3: The achromatic magnetic lens system.

two-stage diode has been shown to improve the ion beam divergence in three-dimensional PIC simulations and in low power proton beam experiments [10]. The experiments have also demonstrated that the second acceleration gap can tre operated in a mode where the gap current is dominated by the injected current, leading to a rising impedance history. This shows promise for the LMF diode where it is envisioned that the ion kinetic energy would be ramped in time to allow beam bunching.

A schematic of the geometry for the two-stage extraction ion diode is shown in Figure 4. A single magnetic field region used to insulate against electron flow across the gap is divided into two accelerating regions by the addition of a mid-gap electrode. The team is allowed to propagate to the second gap by making the mid-gap electrode from a mesh or a thin foil. The electrode allows beam transport between stages but isolates the accelerating electric fields, the beam magnetic field, and the diamagnetic effects of the gap electrons in the two gaps. In the first stage the ion current is limited only by the ion space charge and the effective anode-cathode gap. In the second stage the ion current is limited by the injected current from the first stage (assuming the electrode does not emit a significant ion current). Separation of the electron dynamics in the two stages can lead to a divergence reduction in the second stage. If the current in the second stage is controlled by the injected current, independent control of the voltage is possible and thus voltage ramping of the beam may be attained more easily than for a single stage diode.

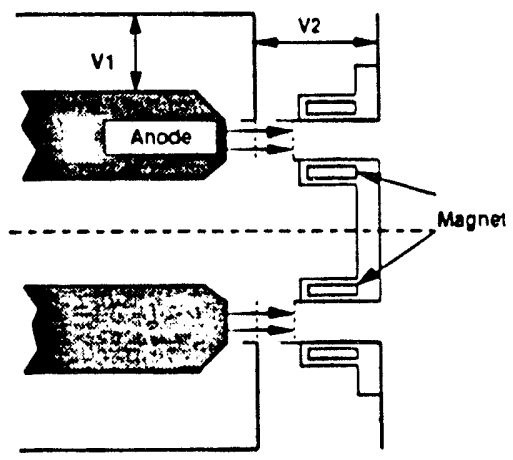

Figure 4: The two-stage extraction ion diode concept. 
In order to supply the on-target peak power pulse of 650 TW (the B-module contribution), each of the twelve " $B$ " module ion beams must deliver a peak on-target power of $54 \mathrm{TW}$ with the aforementioned fwhm of $1.2 \mathrm{~cm}$. With a bunching factor of 2 each diode must supply a peak ion beam power of 27 TW with a voltage ramp from 28 to 35 MV. Accounting for inefficiencies in beam generation, we project that the electrical feed must have a peak power of 38 TW for each B-module diode.

\section{THE LMF INDUCTIVE VOLTAGE ADDER CONCEPT}

Our 38 TW B-module concept is based upon a scaleup of the successful Hermes-III technology developed at SNL over the past ten years in collaboration with Pulsed Sciences Inc.[4]. At present two design options are being considered for the B modules: one that is composed solely of Hermes-III components and the other made up of larger. 2.6-MV cavities. The B modules can be arranged as two Hermss-III accelerators connected in series (40 cavities in total) or as seventeen 2.6-MV cavities. Besides the triaxial voltage adder and the long extension MITL, a very important new element for the second stage of B modules is the ramping of the voltage from 18 to $26 \mathrm{MV}$. it is anticipated that this will be accomplished by a special shaped design of the second stage pulse forming lines to provide the necessary voltage pulse profile at the cavities.

Experiments on Hermes-III are usually done in negative polarity (a mode in which the central stalk is the cathode), and the operating impedance in negative polarity is well understood [11]. For the LMF, we envision positive polarity voltage addition. Experimental studies of the coupling of applied-B extraction diodes to a positive polarity inductive voltage adder are currently being performed in the Sabre facility at SNL[3].

For LMF, the accelerating voltage of the first stage for both $\mathrm{A}$ and $\mathrm{B}$ diodes is a flat $10 \mathrm{MV}$ (not ramped). The second stage voltage for the A modules is a flat $15 \mathrm{MV}$ while the B modules' voltage is ramped from 18 to $26 \mathrm{MV}$ over $40 \mathrm{~ns}$. The cavities of each module are grouped into two stages, and the voltage addition occurs in two separate MITLs nested one inside the other (Figure 5). The center hollow cylinder (anode) of the second stage MITL also serves as the outer cathode electrode for the extension of the first stage voltage adder MITL.

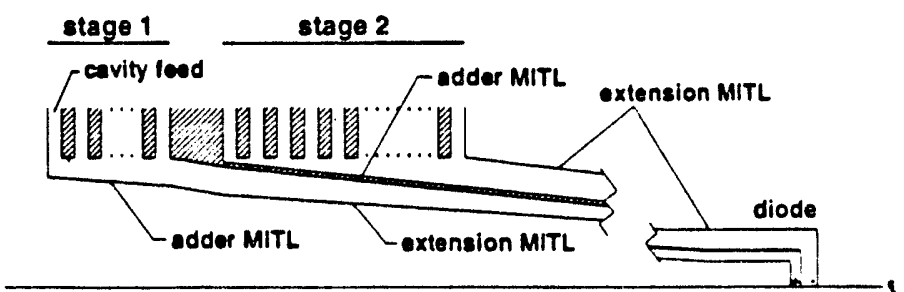

Figure 5: The LMF triaxial voltage adder configuration.
Each voltage adder is connected to the corresponding stage of the diode via a long extension MITL, which timeisolates the diode from the voltage adder. This allows the diode to operate at lower impedance than the accelerator without affecting the voltage adder operation. Undermatching the diode load reduces the sheath electron current in the extension MITL and provides for more efficient pulse power coupling. As shown in Figure 6, the twelve A-modules and twelve B-modules are arranged in three levels surrounding the LMF target chamber.

The A modules are essentially Hermes-III accelerators with 4 more cavities ( 24 total) operating at half power, using half of the 5-ohm pulse-forming and transmission lines that power each of the Hermes-III cavities. The new elements in the LMF A module as compared to Hermes-III are the triaxial voltage adder and the long $(\sim 27 \mathrm{~m})$ possibly curved extension MITL. Hence modest modification of Hermes-III should provide a prototype fo: the LMF A type modules. Details of the LMF linear inductive adder concept are provided in Reference 12.

\section{THE LMF PULSED POWER CONCEPT}

A pulsed power conceptual design that supplies the necessary power to the LMF inductive adder cavities is also based on the successful technologies used in the PBFA-II and Hermes-III facilities. The primary energy store for each of the LMF "B" modules consists of eight 5.5-6.8 MV, $745-975 \mathrm{~kJ}$ oil-insulated Marx generators, very similar to those utilized in PBFA-II. Each Marx generator charges a pair of intermediate storage capacitors which, in turn, supply power to a set of eight (or ten) water-dielectric pulse forming lines. Our choice for discharging the intermediate storage capacitors is the PBFA-II Rimfire laser triggered gas switch, which is presently operating (in PBFA-II) with parameters nearly adequate for our LMF concept. Because the first gap of the two-stage diode will require a relatively flat voltage pulse shape to drive it, and the second gap requires a specified voltage ramp, two pulse forming line (PFL) geometries are required. The first stage PFL will be a straight coaxial line, while the second stage involves a stepped geometry. The PFL's are designed to feed the appropriate power to the Hermes-III type inductively

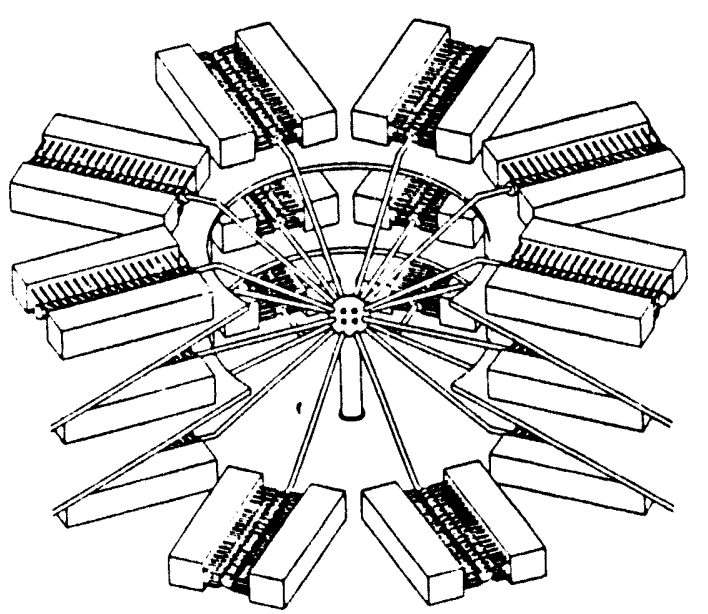

Figure 6: Module arrangement of the light ion LMF. 
isolated cavities. The LMF cavities are designed for field stresses as high as our calculations would reasonably allow, and yet result in a relatively low inductance with a degree of conservatism that is compatible with the HermesIII experience. A reasonable LMF pulsed power design is detailed in Reference 13.

\section{SCALE-UP FROM PRESENT TECHNOLOGY}

The LMF concept described in the previous sections is based upon scaleups and predicied performances of various technologies presently under development at SNL. A comparison of the present status vs. the LMF requirement for several key technologies is shown in Table I. In general, the LMF pulsed power technologies represent relatively modest extrapolations from present levels. In the area of voltage addition and MITL operation, the factor of two scaleup in power (from the existing Hermes-III) is fairly modest, but the positive polarity and triaxial geometry features of the LMF modules add significant uncertainty to the extrapolation.

The greatest technological advances required for the LMF are clearly in the areas of beam generation, transport, bunching, and focusing at high power. The 27 TW, two-stage extraction ion diode projected for the LMF can be compared to the present $\sim 10 \mathrm{TW}$ of total ion beam power routinely generated in the existing PBFA-II single stage barrel diode. Ion beam transpori and bunching have been demonstrated at low power levels, but experiments at the $\sim 10$ TW level have yet to be performed. At present. intensity increase and ion hohlraum physics have been emphasized in experiments using the high power PBFA-II ion beams. The present $2-4 \mathrm{TW} / \mathrm{cm}^{2}$ achieved with lithium and proton beams with a single barrel diode and $15 \mathrm{~cm}$ standoff ( $20 \mathrm{mrad}$ divergence) in PBFA-II can be compared with the $60 \mathrm{TW} / \mathrm{cm}^{2}$ (total for all twelve B. module beams) required with a 6 mrad divergence and $1 \mathrm{~m}$ final focusing distance for the LMF. The 1000-1500 TW/g specific power deposition of present-day PBFA-II lithium beam hohlraums is compared to the 5000-10000 $\mathrm{TW} / \mathrm{g}$ level (which represents the total supplied by the twelve B-module beams) required for the LMF hohlraum.

\section{LIBRA -. A LIGHT ION BEAM REACTOR ASSESSMENT}

The LIBRA study [5-7] is a self-consistent conceptual design of a light ion driven commercial fusion power reactor. A major goal of the LIBRA work was to understand the potential of light ion fusion as the basis for small, yet economically attractive power reactors. This was done by completing a self-consistent point design, evaluating its cost, and cost scaling the design to different power levels.

For LIBRA, it is envisioned that JCF targets are imploded by $4 \mathrm{MJ}$ time-shaped pulses of $30 \mathrm{MeV}$ lithium ions with a rep rate of $3-12 \mathrm{~Hz}$ and net electrical power of 300-1200 MW. The fusion yield of each target $(320 \mathrm{MJ})$ is less than in LMF, but the more optimistic gain is comparable to other ICF reactor conceptual design
Table I

LMF Extrapolations from Present Technology

\begin{tabular}{lcc}
\multicolumn{1}{c}{ Technology } & Present Status & LMERequirements \\
Marx generator & $370 \mathrm{~kJ}, 5 \mathrm{MV}$ & $860 \mathrm{~kJ}, 6 \mathrm{MV}$ \\
L.T. gas switch & $5 \mathrm{MV}, 340 \mathrm{kA}$ & $6 \mathrm{MV}, 640 \mathrm{kA}$ \\
Voltage Adder & $20 \mathrm{MV}, 16 \mathrm{TW}$ & $35 \mathrm{MV}, 38 \mathrm{TW}$ \\
Diode Ion Power & $10 \mathrm{TW}$ & $27 \mathrm{TW}$ \\
Transport & $\sim 1 \mathrm{TW}, 1.5 \mathrm{~m}$ & $>27 \mathrm{TW}, 4 \mathrm{~m}$ \\
Bunching & $<1 \mathrm{TW}, 2 \mathrm{x}$ & $27.54 \mathrm{TW}$ \\
Beam Spot Size & $0.6 \mathrm{~cm} \mathrm{fwhm}$ & $1.2 \mathrm{~cm} \mathrm{fwhm}$ \\
On-Target Intensity & $4 \mathrm{TW} / \mathrm{cm}^{2}$ & $60 \mathrm{TW} / \mathrm{cm}^{2}$, total \\
Target Deposition & $1000-1500 \mathrm{TW} / \mathrm{g}$ & $5000-10000 \mathrm{TW} / \mathrm{g}$
\end{tabular}

assumptions. Figure 7 is an isometric view of the LIBRA drivers and reactor chamber.

Two types of LIBRA reactor chambers have been considered -. LIBRA[6] and LIBRA-LiTE[7]. A key difference between the two designs is the assumption of ballistic focusing in LIBRA-LiTE vs. channel transport in LIBRA. More recently, an assessment of the promise of self-pinched beam propagation for light ion fusion reactors (LIBRA-S) has begun [14]. Self-pinched ion beam propagation, while less studied than the channel or ballistic schemes, might eventually represent the most attractive concept for a light ion beam reactor.

The LIBRA ion diodes must operate in a repetitive mode with an extraction geometry. The LIBRA diode concept is an applied magnetic field extractor diode with an annular anode made of a porous material that is continually wetted with liquid lithium. The lithium provides both a constantly replenished ion source and a means of carrying away the heat of diode electrons. Experiments at SNL have shown promise for the liquid lithium / porous anode concept [15]. The LIBRA ion source density and microdivergence would be similar to the LMF. A review of repetitive ion diode concepts and experimental efforts (which are presently in a very early stage of development) is given in Reference 16.

The conceptual design of a repetitive $30 \mathrm{MV}$ driver for LIBRA is presented in Reference 17. The driver design is very similar to the system previously described

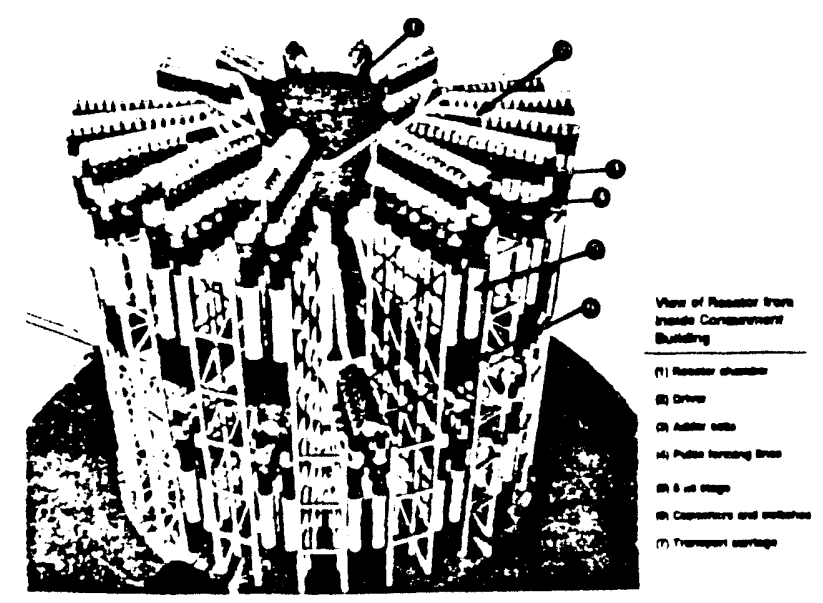

Figure 7: A view of the LIBRA-LiTE reactor from inside the containment building (from Ref. 7). 
for the light ion LMF concept. Like the LMF, it also uses the Hermes-III type of linear inductive voltage addition technology. The requirement for repetitive operation is the primary technical advance required beyond the LMF technology. It is anticipated that this advance will be achieved by replacing the water dielectric switches used in LMF with magnetic (saturable reactor) switches like those developed at SNL[18]. As is suggested in Reference 17, the LMF Marx generators might be replaced with magnetic pulse compressors powered by long-life switches such as thyratrons or semiconductors or perhaps by rotating machines.

An important measure of the flexibility in the light ion beam fusion concept is the cost of electricity from such a power plant. In Reference 5, a costing analysis for the LIBRA reactor has been performed using the FUSCOST code[19] with input from both magnetic fusion energy (MFE) and other ICF costing sources. The direct capital cost of a 330 MWe LIBRA design is estimated to be $\$ 2900 / \mathrm{kWe}$, while a $1200 \mathrm{MWe}$ reactor would cost approximately $\$ 1300 / \mathrm{kWe}$. The larger LIBRA reactor benefits from the economy of scale by a factor of almost $50 \%$ in $\$ / \mathrm{kWe}$.

It is interesting to compare the LIBRA direct capital costs to those calculated for other fusion reactor designs published over the past 20 years. When LIBRA is compared to other reactor designs at the $1000 \mathrm{MWe}$ level and above, it is quite competitive. More importantly, LIBRA is also competitive at a lower electrical power level which reduces the per-unit capital investment required by utilities.

\section{CONCLUSIONS}

The SNL light ion ICF program is directed toward validating light ions as an efficient driver for highperformance ICF targets, acquiring the data necessary to scale target output to high yield, and developing "standoff" capability for high yield applications. The generation and focusing of high intensity ion beams, the conversion of high intensity :on beam energy into $x$-rays, and the smoothing of the radiation drive at the capsule ablation surface are topics of active experimental and theoretical research at SNL. The LMF conceptual design study provides a long term path of specific goals and requirements that must be met by the light ion target physics, standoff, focusing, beam generation, and pulsed power programs. The LIBRA conceptual design study [5] indicates that light ion beam driven fusion is an excellent candidate for small, economic power plants of $\sim 500 \mathrm{MWe}$. It is encouraging to note that light ions represent an emerging ICF driver technology that is potentially capable of satisfying both near-term defense applications as well as long-term commercial energy applications of inertial confinement fusion.

This work performed at Sandia National Laboratories is supported by the U. S. Department of Energy under contract DE-AC04.76DP00789.

$$
94928 \cdots 2,
$$

\section{REFERENCES}

1. U.S. Department of Energy Office of Inertial Confinement Fusion (DP-28), "Laboratory Microfusion Capability Study -- Phase III Report,” DOE/DP-0017. May, 1993.

2. B. N. Turman, et al., "PBFA-II, A 100TW Pulsed Power Driver for the Inertial Confinement Fusion Program," Proc. 5th IEEE Pulsed Power Conf., Arlington, VA. June 10-12, 1985.

3. M. E. Cuneo, et al., "Observation of Reflected Waves on the SABRE Positive Polarity Inductive Adder MITL," Proc. 9th IEEE Pulsed Power Conf., Albuquerque, NM, June 21-23, 1993.

4. J. J. Ramirez, et al., "Hermes-III -. A 16 TW, Short Pulse Gamma Ray Simulator," Proc. 7th Int. Conf. on High Power Particle Beams, Karlsruhe, Germany, July 4-8, 1988.

5. B. Badger, et al., "LIBRA -- A Light Ion Beam Fusion Conceptual Reactor Design", Univ. of Wisconsin Rpt. UWFDM-800; also, Kernforschungszentrum Karlsruhe Rpt. KfK-4710 (1990).

6. G. A. Moses, et al., "LIBRA -. A Light Ion Beam Inertial Confinement Fusion Reactor Conceptual Design," Lasers and Particle Beams, Z, 721 (1989).

7. G. L. Kulcinski, et al., "LIBRA-LiTE: A $1000 \mathrm{MWe}$ Reactor," J. Fusion Energy, 10, 339 (1991).

8. C. L. Olson, Proc. 1988 LINAC Conf., CEBAF Rpt. 89-001, p. 34, June, 1988.

9. R. R. Peterson, University of Wisconsin, private communication, 1993.

10. T, Lockner, et al., "Theoretical and Experimental Studies of the 2-Stage Ion Diode," Proc. 9th IEEE Pulsed Power Conf., Albuquerque, NM, June 21-23, 1993.

11. C. W. Mendel,Jr., el al., Laser and Particle Beams. 1. 311 (1983).

12. M. G. Mazarakis, et al., "The LMF Triaxial MITL Voltage Adder System," Proc. 9th IEEE Pulsed Power Conf., Albuquerque, NM, June 21-23, 1993.

13. D. L. Smith, et al.. "A Pulsed Power Design for the Linear Inductive Accelerator Modules for the Laboratory Microfusion Facility," Proc. 9th IEEE Pulsed Power Conf., Albuquerque. NM. June 21-23, 1993.

14. R. R. Peterson, et al., "The Promise of Self-Pinched Beam Propagation to Light Ion Fusion Reactors," Univ. of Wisconsin Rpt. UWFDM-918 (1993).

15. K. W. Beig, et al., Trans Plasma Sci., (1989).

16. J. Greenly, "Concepts for Repetitive Ion Diodes." Proc. Beams '88, pp. 137-147 (1988).

17. I. Smith et al., "Conceptual Design of a $30 \mathrm{MV}$ Driver for LIBRA." Proc. Beams '88, pp. 127-136 (1988).

18. E. L. Neau, et al., "COMET-II, A Two-Stage , Magnetically Switched Pulsed Power Module," Proc. 16th IEEE Power Modulator Symp., p. 292 (1984).

19. Z. Musicki, "FUSCOST: A PC-Based Menu Driven Program for Economic Analysis of Fusion Facilities." Proc. 12th Symp. on Fusion Engineering, Monterey, Oct.. 1987. 

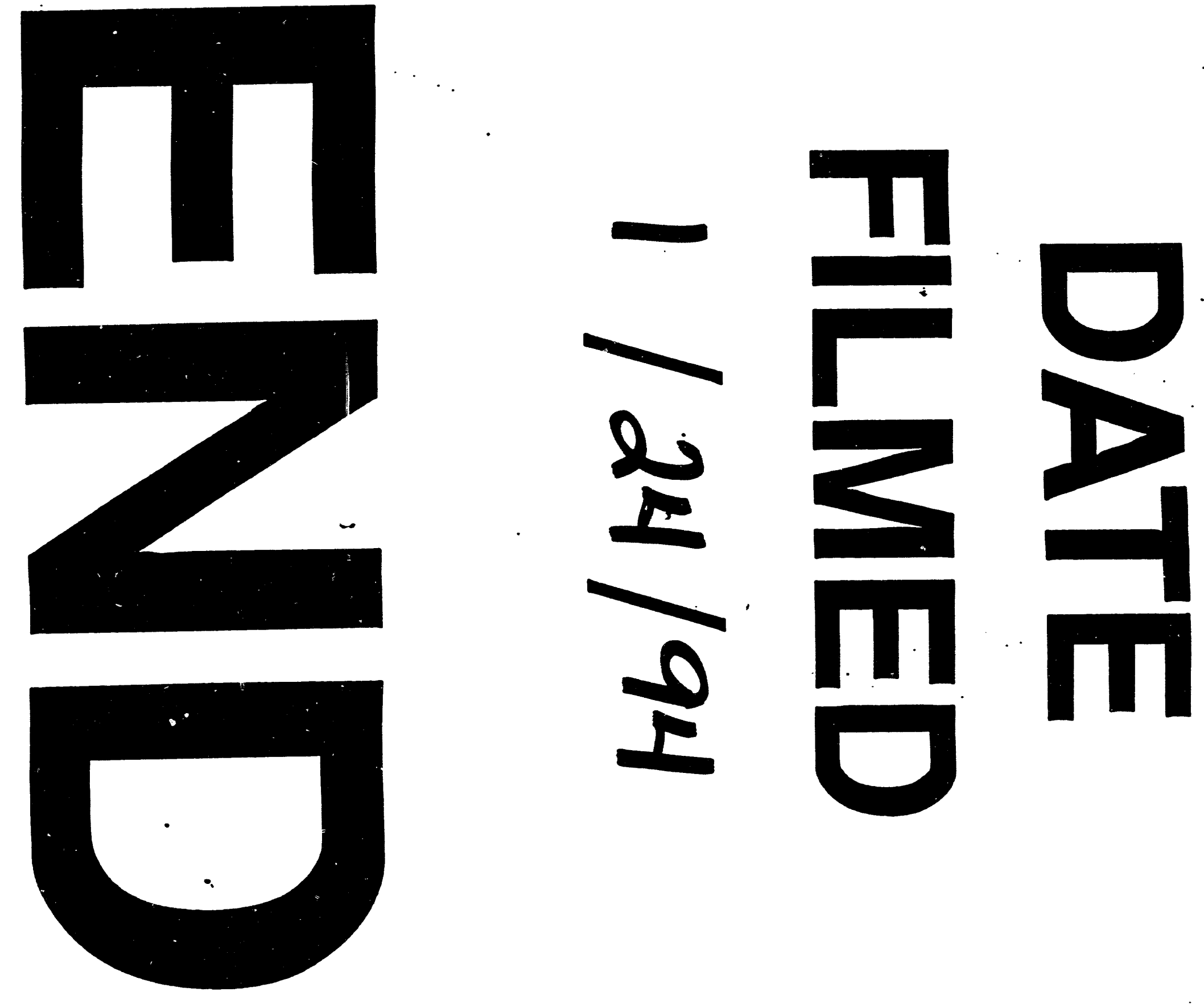
